Cite this: Phys. Chem. Chem. Phys., 2014, 16, 5382

Received 6th November 2013 Accepted 14th January 2014

DOI: $10.1039 / c 3 c p 54704 c$

www.rsc.org/pccp

\title{
Hydrogen storage on metal oxide model clusters using density-functional methods and reliable van der Waals corrections $\dagger$
}

\author{
Julian Gebhardt, ${ }^{a}$ Francesc Viñes, ${ }^{\text {ab }}$ Patrick Bleiziffer, ${ }^{a}$ Wolfgang Hieringer ${ }^{a}$ and \\ Andreas Görling ac
}

\begin{abstract}
We investigate the capability of low-coordinated sites on small model clusters to act as active centers for hydrogen storage. A set of small magic clusters with the formula $(X Y)_{6}(X=M g, B a, B e, Z n, C d, N a$, $\mathrm{Li}, \mathrm{B}$ and $\mathrm{Y}=\mathrm{O}, \mathrm{Se}, \mathrm{S}, \mathrm{F}, \mathrm{I}, \mathrm{N}$ ) and a "drumlike" hexagonal shape showing a low coordination number of three was screened. Oxide clusters turned out to be the most promising candidates for hydrogen storage. For these ionic compounds we explored the suitability of different van der Waals (vdW) corrections to density-functional calculations by comparing the respective $\mathrm{H}_{2}$ physisorption profile to highly accurate $\operatorname{CCSD}(T)$ (Coupled Cluster Singles Doubles with perturbative Triples) calculations. The Grimme D3 vdW correction in combination with the Perdew-Burke-Ernzerhof exchange-correlation functional was found to be the best approach compared to $\operatorname{CCSD}(\mathrm{T})$ hydrogen physisorption profiles and is, therefore, suited to study these and other light metal oxide systems. $\mathrm{H}_{2}$ adsorption on sites of oxide model clusters is found to meet the adsorption energy criteria for $\mathrm{H}_{2}$ storage, with bond strengths ranging from 0.15 to $0.21 \mathrm{eV}$. Energy profiles and estimates of kinetic constants for the $\mathrm{H}_{2}$ splitting reaction reveal that $\mathrm{H}_{2}$ is likely to be adsorbed molecularly on sites of $(\mathrm{MgO})_{6},(\mathrm{BaO})_{6}$, and $(\mathrm{BeO})_{6}$ clusters, suggesting a rapid $\mathrm{H}_{2}$ uptake/release at operating temperatures and moderate pressures. The small mass of beryllium and magnesium makes such systems appealing for meeting the gravimetric criterion for $\mathrm{H}_{2}$ storage.
\end{abstract}

\section{Introduction}

Hydrogen has been proposed to be the best substitute for fossil fuels for a future clean, sustainable, and environmentally friendly energy economy. This is mostly due to its abundance and the harmless release of water upon combustion. However, its usage is presently impeded due to the absence of safe and economically viable techniques for its on-board storage. Conventional methods of $\mathrm{H}_{2}$ storage involve liquefaction or compression, but are of little use for practical requirements; liquefaction is only viable at ultra-cold temperatures around $20 \mathrm{~K}$ and gas compression needs very high pressures of about 200-300 bars.

\footnotetext{
${ }^{a}$ Lehrstuhl für Theoretische Chemie, Universität Erlangen-Nürnberg and Interdisciplinary Center of Molecular Materials, Egerlandstraße 3, D-91058 Erlangen, Germany

${ }^{b}$ Departament de Quimica Física and Institut de Química Teòrica i Computacional (IQTCUB), Universitat de Barcelona, c/Martí i Franquès 1, 08028 Barcelona, Spain. E-mail: francesc.vines@ub.edu

Interdisciplinary Center for Interface Controlled Processes, Egerlandstraße 3, D-91058 Erlangen, Germany

† Electronic supplementary information (ESI) available. See DOI: 10.1039/ c3cp54704c
}

Because of this, many research efforts have been devoted to find a material that enables $\mathrm{H}_{2}$ storage under ambient operating conditions. In this context the Department of Energy (DOE) of the United States of America has outlined the properties required for $\mathrm{a}_{2}$ storage material: it must have a gravimetric storage capacity of at least 5.5 weight percentage (wt\%) within uptake/release temperatures between -40 and $60{ }^{\circ} \mathrm{C}-233$ to $333 \mathrm{~K}^{1}$ In addition to the gravimetric criterion, there is a second crucial quantity for suitable hydrogen storage materials, namely the adsorption strength of $\mathrm{H}_{2}$ for the storage material. ${ }^{2}$ On the one hand, the adsorption energy should be at least $0.16 \mathrm{eV}$ in order to ensure a rapid gas uptake at a charging pressure of circa 30 bar. On the other hand, the adsorption energy should not be too large in order to permit a fast $\mathrm{H}_{2}$ desorption at a discharging pressure of around 1.5 bar, resulting in a desired adsorption energy range of usually $0.16-0.26 \mathrm{eV} .^{3}$

Early investigations explored the usage of hydrides and hydrates $;^{4-7}$ whereas the former meet the condition of $5.5 \mathrm{wt} \%$ storage, the high temperature of desorption, the hydride instability, the process irreversibility, and their high costs remain key impediments. ${ }^{8}$ On the other hand, large pressures are needed for the formation of hydrates. ${ }^{6}$ Consequently other materials 
have been investigated, in particular, materials including light elements like $\mathrm{Li}, \mathrm{Na}, \mathrm{Mg}$, and $\mathrm{C}$ in order to meet the gravimetric requirements.

Carbon-based materials are appealing due to their accessibility, variety, and the small mass of carbon, and have triggered many studies that investigated the $\mathrm{H}_{2}$ storage in and on them. Recent studies on alkali doped carbon nanotubes reported a moderate $\sim 5 \mathrm{wt} \%$ storage capability at cryogenic temperatures, ${ }^{9}$ but a drastically reduced capacity of $0.1-0.5 \mathrm{wt} \%$ at room temperature and a pressure of 30 bar. Similar results are found for fullerenes: initially research on nickel and titanium decorated $\mathrm{C}_{60}$ revealed a gravimetric concentration above the DOE requirement. ${ }^{10,11}$ However, newer experimental evidence damped the expectations for storing a considerable amount of hydrogen inside such doped buckyballs. ${ }^{12}$

Another class of materials which has attracted much attention, Metal-Organic Frameworks (MOFs), are crystalline composites consisting of metal ions linked together by organic ligands which generate nanopores. MOFs are quite versatile structures whose surface area can be controlled via the employed organic ligand. These compounds feature high gravimetric hydrogen capacities at cryogenic temperatures-typically in between 77 and $87 \mathrm{~K}^{3}-$ e.g., one of the highest capacities reported so far is $9.95 \mathrm{wt} \%$ at $77 \mathrm{~K}$ and 56 bar for the so-called NU-100 MOF. $^{13}$ However, because of the low binding energy of hydrogen molecules that is dominated by weak van der Waals (vdW) interactions, with strengths of typically $0.05-0.12 \mathrm{eV},{ }^{14}$ all MOFs suffer from a dramatic decrease of the $\mathrm{H}_{2}$ storage capacity upon increasing temperature.

In summary, no material has been found that meets the above criteria for hydrogen storage yet, a milestone which is planned to be achieved by the year 2017. ${ }^{1}$ Therefore, in the present study, we consider another class of compounds as possible hydrogen storage materials. We are screening a broad set of ionic clusters of the formula $(\mathrm{XY})_{6}$ with $\mathrm{X}=\mathrm{Mg}, \mathrm{Ba}, \mathrm{Be}, \mathrm{Zn}$, $\mathrm{Cd}, \mathrm{Na}, \mathrm{Li}, \mathrm{B}$ and $\mathrm{Y}=\mathrm{O}, \mathrm{Se}, \mathrm{S}, \mathrm{F}, \mathrm{I}, \mathrm{N}$ using density-functional (DF) calculations. The low-coordinated sites of these ionic model clusters are interesting active centers for potential hydrogen storage materials. The choice of size and shape is not arbitrary; in many cases these clusters have a particularly high stability, ${ }^{15}$ often referred to as magic clusters, as found, e.g., in cluster beam experiments on $\mathrm{MgO} .{ }^{16,17}$ Nevertheless, clusters of the formula $(\mathrm{XY})_{6}$ are too small to be synthesized in a routine fashion in large quantities at present. However, techniques to produce somewhat larger ionic clusters, including oxides, are being developed and the clusters of formula $(\mathrm{XY})_{6}$ of the present study serve as models, providing a first insight into the hydrogen storage capacities of larger, better accessible clusters. Furthermore, low-coordinated sites, similar to the ones in the studied clusters, are present in nanorods or lowdensity polymorphs of the studied composites.

A crucial question in this context is whether standard DF calculations are adequate to acquire realistic estimates of the interaction of hydrogen molecules with ionic metal centers. The question arises because standard DF methods do not describe long-range dispersion interactions, ${ }^{18}$ which are vital in the $\mathrm{H}_{2}$ storage processes based on physisorption. This shortcoming of standard DF methods can be overcome by applying semiempirical corrections, methods that have proven to yield good results for various systems. ${ }^{19,20}$ The treatment of ionic compounds, however, is not straightforward and requires special care because of the dependence of semi-empirical corrections on polarizabilities, which are strongly affected by the ionic character of a compound. Here, we tackle this problem by applying different vdW corrections to a standard DF and benchmark the hydrogen adsorption profiles of our most promising $(\mathrm{XY})_{6}$ clusters against highly accurate $\operatorname{CCSD}(\mathrm{T})$ (Coupled Cluster Singles Doubles with perturbative Triples) calculations, that represent one of the most accurate $a b$ initio methods for the description of dispersion interactions in electronic systems. ${ }^{21,22}$

\section{Computational details}

DF calculations were carried out using the Vienna $A b$ initio Simulation Package VASP ${ }^{23}$ in conjunction with the projectoraugmented wave method of Blöchl for the description of core electrons. ${ }^{24}$ A plane-wave kinetic energy cutoff of $415 \mathrm{eV}$ was chosen in all calculations. Energies were converged selfconsistently to $10^{-6} \mathrm{eV}$ employing a Gaussian smearing of $0.05 \mathrm{eV}$. The final energy values were corrected to $0 \mathrm{~K}$ (no smearing). In the geometry optimizations forces acting on ions were required to be below $0.01 \mathrm{eV}^{-1}$. The studied clusters were modeled in cubic unit cells with a side length of $15 \AA$. The size of the unit cells guaranteed a minimum separation of $10 \AA$ between the studied clusters and the translationally repeated replicas. Only the $\Gamma$-point was used to sample the corresponding reciprocal unit cells. Using this procedure energies were converged to well below $0.01 \mathrm{eV}$ as tested by using tighter optimization criteria. Calculations were, by default, performed in a spin-polarized fashion, although test calculations revealed negligible differences when carrying out non-spin-polarized calculations, except when systems contained an odd number of electrons. Reference energies for molecular and atomic hydrogen were carried out likewise. The initial sampling of adsorption geometries on ionic clusters was carried out within the LocalDensity Approximation (LDA) using the Vosko-Wilk-Nusair (VWN) correlation functional. ${ }^{25}$ Further refined geometry optimizations were performed within the Generalized-Gradient Approximation (GGA), employing the Perdew-Burke-Ernzerhof (PBE) exchange-correlation functional.

In order to include dispersion interactions not accounted for in standard LDA or GGA exchange-correlation functionals, different vdW corrections were considered: in particular, the recent approach of Grimme et al., named $\mathrm{D} 3,{ }^{20}$ but also the setup of Ortmann and coworkers, ${ }^{19}$ hereafter labeled O. In the latter case the $C^{6}$ coefficients are constructed from the covalent radii $r$ of the atoms in the system, their polarizabilities $\alpha$, and their ionization potentials $I$. These parameters are well established for atomic systems, and have been proven to accurately describe both organic systems with non-covalent interactions, ${ }^{19,26}$ and interactions with transition metals, 
such as graphene-metal contacts. ${ }^{27-29}$ However, this does not ensure the suitability of the atomic parameterization for ionic systems, where anions are expected to be larger, more easily polarizable, and consequently easier to ionize, whereas the opposite trends are expected for cations. Therefore, we also compared the atomic parameterizations of both vdW corrections to ionic parameterizations.

For the $\mathrm{O}$ correction we constructed a second set of ionic parameters for all considered metal oxides. Ionic radii are taken from the literature, ${ }^{30}$ while static orientationally averaged polarizabilities have been determined via DF response calculations at the B3LYP level ${ }^{31}$ by using the TURBOMOLE (v5.9) program suite. ${ }^{32}$ The ionization potentials have been determined using B3LYP $\triangle$ SCF calculations. Ionization potentials and polarizabilities have been explicitly calculated by treating $\mathrm{X}^{2+}$ ions as single isolated ions, whereas the properties of the $\mathrm{O}^{2-}$ anions have been obtained using $\left[\mathrm{X}_{3} \mathrm{O}\right]^{4+}$ clusters, the geometries of which have been taken from corner sites of the optimized magic clusters. Cations in these $\left[\mathrm{X}_{3} \mathrm{O}\right]^{4+}$ units have either been treated as point charges or full $\mathrm{X}^{2+}$ ions. Since both approaches yielded similar results, only the latter strategy has been pursued and is described here. For the $\mathrm{X}^{2+}$ cations, the TZVP basis set has been used throughout. For the calculations of the $\left[\mathrm{X}_{3} \mathrm{O}\right]^{4+}$ units, the aug-cc-pVTZ basis set has been used for oxygen, while the $\mathrm{SV}(\mathrm{P})$ basis set has been used for the metal atoms. The highest occupied orbital is an oxygen $2 \mathrm{p}$ type in all $\left[\mathrm{X}_{3} \mathrm{O}\right]^{4+}$ units. To extract the approximate $\mathrm{O}^{2-}$ polarizability within the cluster environment, the polarizabilities of the $\mathrm{X}^{2+}$ ions have been subtracted from the total polarizability of the $\left[\mathrm{X}_{3} \mathrm{O}\right]^{4+}$ units. Atomic and ionic parameters for the $\mathrm{O}$ correction are listed in Table 1.

For the D3 method a recent article $^{33}$ provided an ionic parameterization for $\mathrm{MgO}$ with an adjusted parameter for $\mathrm{Mg}^{2+}$ in combination with the standard atomic parameter for the oxygen. This parameterization is compared to the standard parameters for the $(\mathrm{MgO})_{6}$ cluster.

All vdW corrections were benchmarked against $\operatorname{CCSD}(\mathrm{T})$ calculations carried out using the RICC2 program of the TURBOMOLE package (v6.4). For the $(\mathrm{BeO})_{6},(\mathrm{MgO})_{6}$, and $(\mathrm{ZnO})_{6}$ clusters we employed aug-cc-pVTZ ${ }^{34}$ orbital basis sets with the corresponding RI auxiliary basis sets. ${ }^{35}$ For $(\mathrm{BaO})_{6}$ the def2-TZVPP ${ }^{36}$ orbital basis set was used in conjunction with the effective core potential for barium of ref. 37 and the def2-TZVPP

Table 1 Atomic and ionic parameters, encompassing covalent (Pauling ionic $^{30}$ ) radii $r$, ionization potentials $l$, and polarizabilities $\alpha$

\begin{tabular}{|c|c|c|c|c|c|c|}
\hline \multirow[b]{2}{*}{ System } & \multicolumn{3}{|c|}{ Atomic } & \multicolumn{3}{|c|}{ Ionic } \\
\hline & $r / \AA$ & $\mathrm{I} / \mathrm{eV}$ & $\alpha / 10^{-24} \mathrm{~cm}^{-3}$ & $r / \AA$ & $\mathrm{I} / \mathrm{eV}$ & $\alpha / 10^{-24} \mathrm{~cm}^{-3}$ \\
\hline $\mathrm{Ba}$ & 2.15 & 5.2 & 39.70 & 1.35 & 37.0 & 1.55 \\
\hline $\mathrm{Be}$ & 0.90 & 9.3 & 5.60 & 0.31 & 154.1 & 0.06 \\
\hline $\mathrm{Mg}$ & 1.54 & 7.6 & 10.60 & 0.65 & 80.4 & 0.05 \\
\hline $\mathrm{Zn}$ & 1.25 & 9.4 & 7.10 & 0.74 & 40.1 & 0.26 \\
\hline$\left[\mathrm{Ba}_{3} \mathrm{O}\right]^{2+}$ & 0.77 & 11.3 & 1.76 & 1.40 & 25.1 & 4.67 \\
\hline$\left[\mathrm{Be}_{3} \mathrm{O}\right]^{2+}$ & 0.77 & 11.3 & 1.76 & 1.40 & 42.5 & 1.88 \\
\hline$\left[\mathrm{Mg}_{3} \mathrm{O}\right]^{2+}$ & 0.77 & 11.3 & 1.76 & 1.40 & 33.7 & 3.27 \\
\hline$\left[\mathrm{Zn}_{3} \mathrm{O}\right]^{2+}$ & 0.77 & 11.3 & 1.76 & 1.40 & 35.4 & 3.69 \\
\hline
\end{tabular}

RI basis set. ${ }^{38}$ In the RICC2 calculations a frozen core approximation was employed in the case of $(\mathrm{BaO})_{6},(\mathrm{MgO})_{6}$, and $(\mathrm{ZnO})_{6}$.

The adsorption energy of a hydrogen molecule $E_{\text {ads }}^{\mathrm{H}_{2}}$ on a cluster has been calculated to be

$$
E_{\mathrm{ads}}^{\mathrm{H}_{2}}=\left(E_{\mathrm{H}_{2}}+E_{\text {cluster }}\right)-E_{\mathrm{H}_{2} / \text { cluster }}
$$

where $E_{\mathrm{H}_{2} / \text { cluster }}$ is the energy of the combined system consisting of $\mathrm{H}_{2}$ adsorbed on the cluster, and $E_{\mathrm{H}_{2}}$ and $E_{\text {cluster }}$ are the energies of the isolated hydrogen molecule and the isolated cluster, respectively. Within this definition, the more positive the value of the adsorption energy, the stronger is the bonding. Adsorption energies of atomic hydrogen were calculated with respect to molecular hydrogen, i.e., $1 / 2 E_{\mathrm{H}_{2}}$ was taken as the energy reference, which corresponds to a zero hydrogen pressure situation.

Dissociation of adsorbed molecular hydrogen was considered by characterizing the transition states (TS) of the splitting process. The TS were obtained by a two-step procedure: first a Climbing Image Nudged Elastic Band (CI-NEB) ${ }^{39}$ with four intermediate images was performed connecting the molecular and dissociated hydrogen geometries. This first guess was followed by a TS search employing the dimer method for the highest obtained CI-NEB image. ${ }^{40}$ All minima and TS were further validated by a vibrational frequency analysis, carried out by diagonalization of the Hessian matrix constructed numerically from finite differences of analytical gradients by calculating energy changes due to independent displacements of $0.015 \AA$ of every atom in each direction of the unit cell vectors. First and second order TS featured one single or two imaginary frequencies, respectively, while minima featured none.

\section{Results and discussion}

\section{Computational models}

There is a large variety of shapes and atomic coordinations for small composite clusters. Here, we concentrate on clusters with the formula $(\mathrm{XY})_{6}$ and, more precisely, to those compounds whose $(\mathrm{XY})_{6}$ clusters exhibit the so-called drum-like hexagonal form, see Fig. 1. In this case cations and anions have the low coordination number three, enabling one to investigate whether

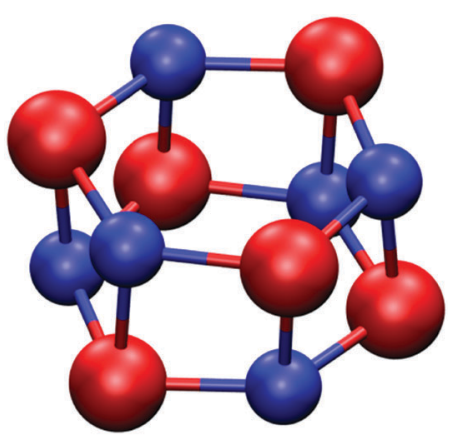

Fig. $1(\mathrm{MgO})_{6}$ as a representative of drumlike hexagonal $(X Y)_{6}$ clusters. Positions of magnesium $(\mathrm{X})$ and oxygen $(\mathrm{Y})$ atoms are depicted by blue and red spheres, respectively. 
the reduced coordination is enhancing the $\mathrm{H}_{2}$ uptake. In many cases these clusters have a particularly high stability, ${ }^{15}$ and are often referred to as magic clusters, as found, e.g., in cluster beam experiments on $\mathrm{MgO},{ }^{16,17}$ which opens the possibility of synthesizing and selecting them.

The many possible sites of $\mathrm{H}_{2}$ physisorption on the $(\mathrm{MgO})_{6}$ cluster were first screened at the VWN level because of the low computational cost and because the VWN functional is known to consistently overestimate binding energies. As a result LDA functionals have been frequently used to describe systems where vdW interactions are crucial, such as the attachment of graphene to $\mathrm{Ni}(111),{ }^{41}$ assuming that the overestimation of conventional binding energies is of the same order as the vdW interaction energy. Eighteen different, highly-symmetric $\mathrm{H}_{2}$ adsorption sites were sampled on the $(\mathrm{MgO})_{6}$ cluster, including parallel $\left({ }^{\|}\right)$and perpendicular $\left({ }^{\perp}\right)$ molecular orientations with respect to the cluster. The hydrogen molecule was placed above anions (X), cations (Y), bonds (XY), the hexagonal (h) or cubic (c) planes of the $(\mathrm{XY})_{6}$ cluster, or in endohedral sites, see Fig. S1 of the ESI. $\dagger$ The results showed that parallel and perpendicular adsorptions over cations or the perpendicular adsorption over anions are the only stable adsorption sites, i.e., all other tested geometries were either driven towards one of these cases, or, in the case of endohedral sites, were thermodynamically unstable, see Table S1 in the ESI. $\dagger$

This initial sampling left us with three stable adsorption sites, namely, $\mathrm{Y}^{\perp}, \mathrm{X}^{\|}$, and $\mathrm{X}^{\perp}$ to be tested on several $(\mathrm{XY})_{6}$ systems ( $\mathrm{Y}^{\|}$was retested for all cases as well but never yielded a minimal structure). In order to stick with the geometries considered for $(\mathrm{MgO})_{6}$ we only selected composites whose drumlike hexagonal cluster is the global minimum, in analogy to $(\mathrm{MgO})_{6}$, or an isomer competitive in energy to the global minimum. These can be oxides $(\mathrm{X}=\mathrm{Mg}, \mathrm{Ba}, \mathrm{Be}, \mathrm{Zn}$ and $\mathrm{Y}=\mathrm{O}),{ }^{42-45}$ selenides $(\mathrm{X}=\mathrm{Zn}$, $\mathrm{Cd}$ and $\mathrm{Y}=\mathrm{Se}),{ }^{46}$ sulfides $(\mathrm{X}=\mathrm{Zn}, \mathrm{Cd}$ and $\mathrm{Y}=\mathrm{S}),{ }^{46,47}$ halides $(\mathrm{X}=\mathrm{Na}, \mathrm{Li}$ and $\mathrm{Y}=\mathrm{F}, \mathrm{I}),{ }^{48,49}$ and the $(\mathrm{BN})_{6}$ nitride. ${ }^{50}$ The geometry optimizations revealed that oxides are the most promising systems for hydrogen storage, with adsorption energies at the VWN level in the range of $\sim 0.3$ to $0.4 \mathrm{eV}$, see adsorption energy values in Table S2 of the ESI. $\dagger$ This finding is in line with the enhanced $\mathrm{H}_{2}$ uptake found on MOFs having $\left(\mathrm{MO}_{4}\right)$ cluster nodes $(\mathrm{M}=\mathrm{Be}, \mathrm{Mg}$, $\mathrm{Zn).}{ }^{51,52}$ Other composites, although giving promising results, were not further considered, i.e., the attention was focused on oxide clusters. At this point, one would guess that the oxygen anions play a crucial role in the hydrogen storage process. However, only in the $(\mathrm{BaO})_{6}$ system is oxygen the preferred adsorption site, whereas adsorption at the cation is more stable for $(\mathrm{BeO})_{6},(\mathrm{MgO})_{6}$, and $(\mathrm{ZnO})_{6}$.

\section{Description of vdW forces}

In the following, a more thorough investigation of the $\mathrm{H}_{2}$ adsorption on the promising $(\mathrm{XO})_{6}(\mathrm{X}=\mathrm{Mg}, \mathrm{Be}, \mathrm{Ba}, \mathrm{Zn})$ oxide clusters has been carried out. To this end adsorption profiles of a single hydrogen molecule approaching its respective most stable adsorption site on each cluster have been obtained by varying the $d(\mathrm{H}-\mathrm{X})$ or $d(\mathrm{H}-\mathrm{O})$ distance with otherwise fixed

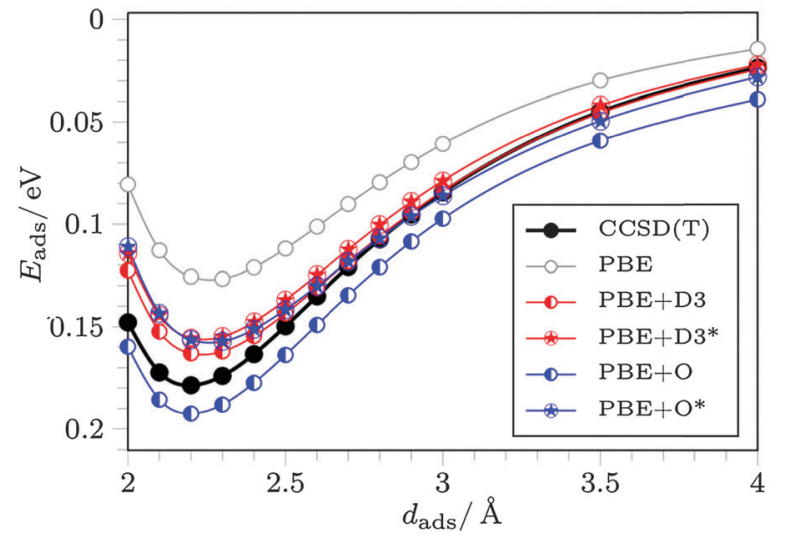

Fig. 2 Adsorption energy profile with varying adsorption distance of a hydrogen molecule on $\mathrm{X}^{\|}$site on $(\mathrm{MgO})_{6}$ for different vdW corrections due to Grimme (D3) and Ortmann (O) with standard atomic and ionic parameters (indicated by a star) compared to $\operatorname{CCSD}(T)$ reference values.

geometries at different computational levels. For all computational levels the cluster was fixed to the respective PBE optimized geometry. The hydrogen bond length was set to the optimized $\operatorname{CCSD}(\mathrm{T})$ value $(0.74 \AA)$. PBE was used as a basis for calculations including the Ortmann or Grimme corrections.

PBE and vdW-corrected adsorption profiles (adsorption energies versus adsorption distance)-either with atomic or ionic parameters (see Computational details)—have been compared to the corresponding $\operatorname{CCSD}(\mathrm{T})$ profiles, considered as a reliable reference for the interaction of a hydrogen molecule with the present oxide clusters, see Fig. 2 and Fig. S2 (ESI $\dagger$ ). Only profiles for the most stable adsorption position on each cluster have been investigated. In all the cases considered PBE values clearly underestimate the interaction energy by $\sim 0.04$ to $0.08 \mathrm{eV}$, as expected due to the absence of a proper description of long range dispersive forces, see Fig. 2 and Fig. S2 (ESI $\dagger$ ). This underlines the need for a suitable description of vdW forces when studying $\mathrm{H}_{2}$ adsorption on ionic systems, given that the contribution of dispersive forces to the bond strength can be as high as $\sim 40 \%$.

For a more in-depth analysis we focused on the $(\mathrm{MgO})_{6}$ case shown in Fig. 2. PBE results underestimate the $\mathrm{H}_{2}$ bonding at the $\mathrm{X}^{\|}$site by $\sim 0.06 \mathrm{eV}$ compared to $\operatorname{CCSD}(\mathrm{T})$ results. The $\mathrm{X}^{\|}$site preference was also recently found on larger tubular $\mathrm{MgO}$ clusters, with a binding strength of $0.09 \mathrm{eV}$ as calculated at the B3LYP level. ${ }^{53}$ In another recent B3LYP study on positively charged $\left[(\mathrm{MgO})_{5}\right]^{+}$and $\left[(\mathrm{MgO})_{7}\right]^{+}$clusters the $\mathrm{X}^{\|}$site was also preferred, with Zero Point Energy (ZPE) adsorption energies in the range of $0.11-0.16 \mathrm{eV} .{ }^{54}$ In this sense, the present results are consistent with previous calculations carried out on similar systems. Note that the lowered coordination of the cluster ions is ostensibly enhancing the $\mathrm{H}_{2}$ adsorption strength. For instance, a LDA study on $\mathrm{H}_{2}$ adsorption on the $\mathrm{MgO}(001)$ surface found an adsorption energy of $0.05 \mathrm{eV} .^{55}$ Keeping in mind the overbinding tendency of LDA, a proper comparison can be made with the present LDA value of $0.31 \mathrm{eV}$ for $\mathrm{H}_{2}$ on a $\mathrm{X}^{\|}$site on $(\mathrm{MgO})_{6}$, as found in Table $\mathrm{S} 1$ of the ESI. $\dagger$

Focusing on vdW corrections, Fig. 2 shows that the use of ionic instead of atomic parameters has a substantial effect. 
For instance, the standard $\mathrm{O}$ correction is overestimating the $\mathrm{H}_{2}$-cluster interaction energy by $0.014 \mathrm{eV}$, whereas usage of the ionic parameterization leads to a bonding strength underestimation of $0.035 \mathrm{eV}$. In D3 the bond weakening upon the use of ionic parameters is less pronounced, with a change of barely $0.01 \mathrm{eV}$. Note that in this latter case the ionic parameterization is only applied to magnesium, while atomic parameters are used for oxygen. Thus, if available, the inclusion of ionic parameters on oxygen atoms would attenuate the effect, i.e., the decrease of the magnesium polarizability would be partially counteracted by the increased oxygen polarizability.

The reason for the small difference between ionic and atomic parameters in the D3 case and thus the suitability of the atomic parameters can be attributed to the nature of the method. The $C_{6}$ parameters are interpolated according to the estimated (fractional) coordination number in the studied systems and the coordination numbers and polarizabilities from a specific reference set to each atom. ${ }^{20}$ In the case of magnesium, the reference set includes the hydrides $\mathrm{MgH}$, $\mathrm{MgH}_{2}$, and the atomic parameter. Thus, the reference cases dominating the interpolation are already ionic hydrides and not the atomic magnesium. For example, Bader analysis ${ }^{56}$ performed on $\mathrm{MgH}$ yields magnesium in a charge state of +1.02 , i.e., only $\sim 0.6$ electrons, less oxidized compared to magnesium in molecular $\mathrm{MgO}(+1.65)$ or in the $(\mathrm{MgO})_{6}$ cluster $(+1.61)$, revealing that the atomic parameter in the D3 framework does not refer to a situation of uncharged magnesium atoms but magnesium atoms that are already close to the desired ionic situation.

Due to this and the overlapping effects that are apparent in additive semi-empirical vdW corrections, the reproduction of the $\operatorname{CCSD}(\mathrm{T})$ values is taken as the main indicator of the suitability of each vdW correction. In this sense one would seek, in general terms, a vdW correction that would reproduce the $\operatorname{CCSD}(\mathrm{T})$ values in all the studied cases. This has not been achieved by any of the tested vdW-corrected DF setups. Furthermore, tuning the damping function that is present in all discussed vdW corrections, in principle, would be a possible way of weighting the degree of vdW interactions to the adsorption energy. However, there is no consistent way to get a common setup for all the studied cases, due to the different extent and character of the under/overestimation of the $\mathrm{H}_{2}$ adsorption strength, which depends both on the adsorption site and the oxide cluster. All things considered atomic Grimme D3 seems to be the best compromise: it features the smallest mean deviation from $\operatorname{CCSD}(\mathrm{T})$ values on $\mathrm{X}^{\|}$sites of $(\mathrm{MgO})_{6}$, $(\mathrm{BeO})_{6}$, and $(\mathrm{ZnO})_{6}$ systems, consistently underestimating the bond strength by $0.02-0.03 \mathrm{eV}$, whereas on the $\mathrm{Y}^{\perp}$ site of the $(\mathrm{BaO})_{6}$ cluster this correction only marginally overestimates the bond strength by $0.01 \mathrm{eV}$, see Fig. 2 and Fig. S2 (ESI $\dagger$ ). The utilization of PBE-D3 has an additional benefit: it has been proven to yield a reliable description of the non-covalent interaction between small organic molecules. ${ }^{26}$ Thus, the method seems suitable for testing the $\mathrm{H}_{2}$ interaction on both organic ligands and metal oxide cluster nodes of MOFs.
In the following the PBE-D3 setup is used to study the interaction and dissociation of $\mathrm{H}_{2}$ on the (XO) $)_{6}$ oxide clusters.

\section{$\mathrm{H}_{2}$ and atomic $\mathrm{H}$ adsorption}

The energetic and structural information of the most stable sites for $\mathrm{H}_{2}$ adsorption on $(\mathrm{XO})_{6}$ oxide clusters as calculated at the PBE-D3 level is gathered in Table 2. Typically, parallel adsorption over a cation site is the most preferred $\left(\mathrm{X}^{\|}\right)$, with perpendicular adsorption over an anion being the second most favorable $\left(\mathrm{Y}^{\perp}\right)$, yet normally destabilized by at least $0.08 \mathrm{eV}$ compared to the $\mathrm{X}^{\|}$site. An exception is the $(\mathrm{BaO})_{6}$ cluster, where the $\mathrm{Y}^{\perp}$ site happens to be most stable, and the $\mathrm{X}^{\|}$site is becoming significantly destabilized, probably due to the larger size of barium cations compared to the other considered cations (see Table 1). In all cases a more stable adsorption is accompanied by a smaller adsorption distance of the hydrogen molecule to the cluster and a slightly larger hydrogen bond, indicating the weakening of the hydrogen bond due to the cluster-hydrogen interactions. Note that the $\mathrm{H}_{2}$ vacuum bond length of $0.75 \AA$ is retained for weak adsorption situations. The $(\mathrm{BeO})_{6}$ cluster surprisingly features the largest $\mathrm{H}_{2}$ adsorption energy, followed by the $(\mathrm{MgO})_{6}$ and $(\mathrm{ZnO})_{6}$ clusters, contrary to what was found on MOFs containing $\left(\mathrm{M}_{4} \mathrm{O}\right)$ cluster nodes $(\mathrm{M}=\mathrm{Mg}, \mathrm{Be}, \mathrm{Zn})$, where the magnesium based MOF featured the largest $\mathrm{H}_{2}$ adsorption energy, followed by zinc and beryllium based MOFs. ${ }^{51}$ However, on these MOFs the hydrogen molecules were found to adsorb on oxygen sites, and so the adsorption energy ordering on $\mathrm{Y}^{\perp}$ sites as shown in Table 2 completely supports these previous findings.

Note that $\mathrm{X}^{\|}$adsorption on low-coordinated metal sites of $(\mathrm{MgO})_{6},(\mathrm{BeO})_{6}$, and $(\mathrm{ZnO})_{6}$ magic clusters meets the energetic requirement of $0.16 \mathrm{eV}$ as posed by Bhatia and Myers. ${ }^{2}$ Furthermore, as explained above, one would expect the adsorption energy to be even $0.02-0.03 \mathrm{eV}$ higher according to comparison with the $\operatorname{CCSD}(\mathrm{T})$ calculations. In addition, the physisorption process can be assumed to have no energy barrier which would enable a rapid $\mathrm{H}_{2}$ uptake/release process, a highly desired feature for $\mathrm{H}_{2}$ storage materials. In this sense our results strongly suggest low-coordinated sites on metal oxides, particularly, cation adsorption sites, as appealing active centers for $\mathrm{H}_{2}$ storage.

Adsorption of $\mathrm{H}_{2}$ on $(\mathrm{XO})_{6}$ clusters induces only a small elongation of the $\mathrm{H}_{2}$ bond length of 0.001-0.015 $\AA$, not enough

Table 2 Most stable $\mathrm{H}_{2}$ adsorption positions and corresponding binding energies $E_{\text {ads }}$ on different metal oxide clusters as obtained by PBE-D3 calculations. The closest distance $d(H-X / Y)$ of the hydrogen molecule and a cluster ion ( $\mathrm{X}$ or $\mathrm{Y}$, respectively) is displayed together with the $\mathrm{H}_{2}$ bond length $d(\mathrm{H}-\mathrm{H})$

\begin{tabular}{lllll}
\hline Cluster & Site & $E_{\text {ads }} / \mathrm{eV}$ & $d(\mathrm{H}-\mathrm{X} / \mathrm{Y}) / \AA$ & $d(\mathrm{H}-\mathrm{H}) / \AA$ \\
\hline$(\mathrm{BaO})_{6}$ & $\mathrm{Y}^{\perp}$ & 0.15 & 2.13 & 0.77 \\
& $\mathrm{X}^{\|}$ & 0.04 & 3.43 & 0.75 \\
$(\mathrm{BeO})_{6}$ & $\mathrm{X}^{\|}$ & 0.21 & 1.88 & 0.76 \\
& $\mathrm{Y}^{\perp}$ & 0.05 & 2.50 & 0.75 \\
$(\mathrm{MgO})_{6}$ & $\mathrm{X}^{\|}$ & 0.17 & 2.25 & 0.76 \\
& $\mathrm{Y}^{\perp}$ & 0.09 & 2.28 & 0.76 \\
$(\mathrm{ZnO})_{6}$ & $\mathrm{X}^{\perp}$ & 0.16 & 2.17 & 0.76 \\
& $\mathrm{Y}^{\perp}$ & 0.06 & 2.38 & 0.75
\end{tabular}


Table 3 Most stable adsorption sites and corresponding binding energies of atomic hydrogen on the four considered metal oxide clusters as obtained by PBE-D3 calculations, together with the distance $d(\mathrm{H}-\mathrm{Y})$ of the hydrogen atom to its ionic bonding site. Adsorption energies have been calculated taking half of the $\mathrm{H}_{2}$ energy as the energy reference

\begin{tabular}{llll}
\hline Cluster & Site & $E_{\text {ads }} / \mathrm{eV}$ & $d(\mathrm{H}-\mathrm{Y}) / \AA$ \\
\hline$(\mathrm{BaO})_{6}$ & $\mathrm{Y}$ & -3.14 & 0.98 \\
$(\mathrm{BeO})_{6}$ & $\mathrm{Y}$ & -4.89 & 0.98 \\
$(\mathrm{MgO})_{6}$ & $\mathrm{Y}$ & -0.14 & 0.97 \\
$(\mathrm{ZnO})_{6}$ & $\mathrm{Y}$ & 0.46 & 0.98
\end{tabular}

to indicate that oxide clusters are favoring $\mathrm{H}_{2}$ dissociation. Nevertheless, we further investigated the question of whether $\mathrm{H}_{2}$ would be molecularly stored on such metal oxide clusters or dissociate into hydrogen atoms. To that end the adsorption of atomic hydrogen has been addressed explicitly. Analogously to the hydrogen molecule, site sampling was first systematically investigated at the VWN level on the four oxide clusters $(\mathrm{MgO})_{6}$, $(\mathrm{BaO})_{6},(\mathrm{BeO})_{6}$, and $(\mathrm{ZnO})_{6}$. Results and adsorption sites are shown in Table S3 and Fig. S3 of the ESI, $\dagger$ respectively. According to these preliminary results hydrogen clearly prefers to attach directly on top of cations or anions. These two sites were later on reoptimized at the PBE-D3 level, and the final results are collected in Table 3. In all the cases the formation of $\mathrm{OH}$ hydroxyl groups is found to be the most stable situation, with a characteristic $\mathrm{OH}$ bond length of $\sim 0.98 \AA$. The covalent $\mathrm{OH}$ bond formation prompts, with the exception of $(\mathrm{BaO})_{6}$, the breaking of one cation-anion bond between the two hexagonal facets of the metal oxide cluster, as shown in Fig. 3 for $(\mathrm{MgO})_{6}$. The different behavior of $(\mathrm{BaO})_{6}$ is probably again a result of the increased size of barium atoms and the resulting substantively larger cluster size (the XO bond length along hexagonal facets of the cluster is increased for $\mathrm{X}=\mathrm{Ba}$ by $\sim 0.5$ to $0.9 \AA$ compared to $\mathrm{X}=\mathrm{Zn}, \mathrm{Mg}(\sim 1.9 \AA)$ and $\mathrm{X}=\mathrm{Be}(1.56 \AA)$, respectively). Having a look at the adsorption energies we find that only in the case of $(\mathrm{ZnO})_{6}$ adsorption of atomic hydrogen is thermodynamically more stable than adsorption of molecular hydrogen. For the other three cases atomic hydrogen adsorption is less stable than molecular adsorption and even thermodynamically unstable compared to the isolated reference systems. $(\mathrm{MgO})_{6}$ has an

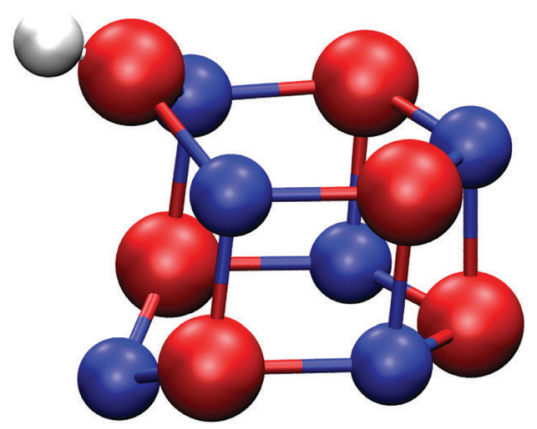

Fig. 3 A single hydrogen atom adsorbed on a $\mathrm{Y}$ site of $(\mathrm{MgO})_{6}$ demonstrating the structural changes of the smaller $(X Y)_{6}$ clusters upon hydrogen adsorption. Magnesium, oxygen, and hydrogen atoms are depicted by blue, red, and white spheres, respectively.
Table 4 Most stable conformations of two hydrogen atoms co-adsorbed on the considered metal oxide clusters, and their binding energy as obtained from PBE-D3 calculations. The distances $d(\mathrm{H}-\mathrm{X})$ and $d(\mathrm{H}-\mathrm{Y})$ are the closest distances of hydrogen atoms to their cation or anion bonding sites, respectively. Adsorption energies have been calculated with respect to molecular hydrogen

\begin{tabular}{llcll}
\hline Cluster & Site & $E_{\text {ads }} / \mathrm{eV}$ & $d(\mathrm{H}-\mathrm{X}) / \AA$ & $d(\mathrm{H}-\mathrm{Y}) / \mathrm{A}$ \\
\hline$(\mathrm{BaO})_{6}$ & $\mathrm{YY}$ & 0.36 & - & 0.98 \\
& $\mathrm{XY}$ & -0.15 & 2.49 & 0.97 \\
$(\mathrm{BeO})_{6}$ & $\mathrm{XY}$ & -0.03 & 1.38 & 0.97 \\
& $\mathrm{XY}$ & 0.02 & 1.37 & 0.97 \\
$(\mathrm{MgO})_{6}$ & $\mathrm{XY}$ & 0.39 & 1.75 & 0.97 \\
$(\mathrm{ZnO})_{6}$ & $\mathrm{XY}$ & 1.11 & 1.53 & 0.98 \\
& $\mathrm{YY}$ & 0.68 & - & 0.98
\end{tabular}

atomic adsorption energy that is only slightly endothermic, while adsorption of atomic hydrogen is endothermic by more than $3 \mathrm{eV}$ in the cases of $(\mathrm{BeO})_{6}$ and $(\mathrm{BaO})_{6}$. On the basis of the above data it seems possible that $\mathrm{H}_{2}$ breaks when adsorbing on $(\mathrm{ZnO})_{6}$ and $(\mathrm{MgO})_{6}$ clusters, whereas $\mathrm{H}_{2}$ splitting seems unlikely on $(\mathrm{BeO})_{6}$ and $(\mathrm{BaO})_{6}$.

Next we consider the possible distribution of two hydrogen atoms adsorbed simultaneously on the oxide clusters at the PBE-D3 level. Geometries with both hydrogen atoms occupying either solely anion sites (YY), cation sites (XX), or a combination of both $\left(\mathrm{XY}, \mathrm{XY}^{\prime}\right)$ are studied. Energetic and structural information of the stable conformations is displayed in Table 4, while structural sketches for the most stable sites are depicted in Fig. 4. Here a distinction must be made between the oxides of light (Be and $\mathrm{Mg}$ ) and heavy (Ba and $\mathrm{Zn}$ ) metals. In the former oxides, one of the most stable conformations implies the simultaneous occupation of vicinal cation and anion sites located at different cluster hexagonal facets, here named $\mathrm{XY}^{\prime}$. In $(\mathrm{BeO})_{6}$ a similarly competitive situation is found, but with cation and anion sites on the same hexagonal facet (XY). For heavy metal oxides the XY situation competes with a structure where the two hydrogen atoms occupy two anion sites within the same cluster cubic facet (YY). In all cases adsorption of the second hydrogen atom improves the adsorption energy per hydrogen atom in the most stable conformation compared to adsorption of a single hydrogen atom. As a result, atomic adsorption of two hydrogen atoms is favored against adsorption of molecular hydrogen in all cases but $(\mathrm{BeO})_{6}$. In the cases of barium and magnesium oxide clusters adsorption of atomic hydrogen is slightly favored by roughly $0.2 \mathrm{eV}$. For $(\mathrm{ZnO})_{6}$, however, hydrogen dissociation is favored by almost $1 \mathrm{eV}$. Thus, dissociation of $\mathrm{H}_{2}$ upon adsorption is unlikely to occur on $(\mathrm{BeO})_{6}$; seems possible, but depends on the reaction kinetics for $(\mathrm{MgO})_{6}$ and $(\mathrm{BaO})_{6}$; and is likely on $(\mathrm{ZnO})_{6}$. Such thermodynamic trends may well be maintained for low-coordinated sites of larger oxide clusters and related oxide composite systems.

In order to investigate this further, the reaction kinetics of a possible $\mathrm{H}_{2}$ decomposition is studied in the following. All promising combinations of stable geometries of molecular and dissociated hydrogen on the respective oxides were considered. 


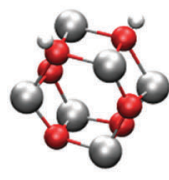

YY

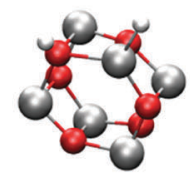

$\mathrm{XY}$

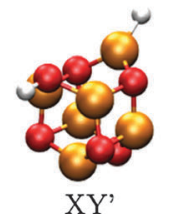

XY'

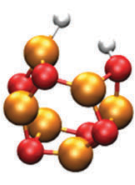

XY

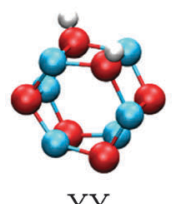

YY

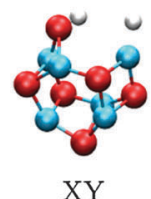

$\mathrm{XY}$

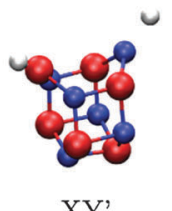

XY'

Fig. 4 Sketches of the most stable conformations of two hydrogen atoms adsorbed on the considered oxide clusters. Atoms are depicted by grey (barium), orange (beryllium) cyan (zinc), blue (magnesium), red (oxygen), and white (hydrogen) spheres.

\section{Kinetics of $\mathrm{H}_{2}$ dissociation}

The structural and energetic information gained in the last section has been used to outline the possible $\mathrm{H}_{2}$ dissociation paths on the oxide clusters. Reaction steps and transition states have been obtained following the procedure described in the Computational details, and were characterized via vibrational frequency analysis. Reaction educts and products have been likewise characterized as minima of the potential energy surface. The vibrational spectra have been used to apply a ZPE correction to the reaction profile, defined as

$$
\mathrm{ZPE}=\frac{1}{2} \sum_{i}^{3 N-6} \nu_{i} h,
$$

where $3 N-6$ is the number of vibrational normal nodes $-3 N-7$ or $3 N-8$ for first and second order TS, respectively-for a nonlinear system containing $N$ atoms, $\nu_{i}$ is the $i$ th vibrational frequency, and $h$ is the Planck constant. The reaction energy profiles obtained for each oxide cluster, depicted in Fig. 5, are discussed in the following.

For the $(\mathrm{ZnO})_{6}$ cluster the $\mathrm{H}_{2}$ dissociation from a $\mathrm{X}^{\|}$site to occupy a XY structure is a clear exothermic process of $0.82 \mathrm{eV}$, with a small energy barrier of $0.34 \mathrm{eV}$ for the hydrogen splitting process. However, the TS is located above the sum of isolated $\mathrm{H}_{2}$ and $(\mathrm{ZnO})_{6}$, which is chosen as reference energy, i.e., set to zero. Therefore, the energy released during the hydrogen molecule adsorption process $-0.09 \mathrm{eV}$ - is not enough to overcome the dissociation energy barrier and thermal energy is required to dissociate hydrogen. Since the energy of the TS lies only $0.24 \mathrm{eV}$ above that of the reference system, however, such a situation is likely to be found even at cryogenic temperatures. For the dissociated hydrogen XY state conversion into the YY geometry can be considered, however, the diffusion step is endothermic by $0.47 \mathrm{eV}$ and the energy barrier of $1.23 \mathrm{eV}$ is quite high. Note that a possible direct conversion of $\mathrm{X}^{\|}$to the YY site was not found. Therefore, such a conversion is unlikely to happen at operating temperatures of 233-333 K. In summary, the XY dissociated structure happens to be the thermodynamic sink, and hydrogen molecules attaching on $(\mathrm{ZnO})_{6}$ clusters are likely to dissociate irreversibly under operating conditions. This is in line with studies showing that $\mathrm{H}_{2}$ splits on $\mathrm{ZnO}$ surfaces forming hydride and hydroxyl moieties. ${ }^{57}$

The reaction path is notably different for the $(\mathrm{MgO})_{6}$ cluster: here, the dissociation of $\mathrm{H}_{2}$ from a $\mathrm{X}^{\|}$site to a $\mathrm{XY}^{\prime}$ conformation features a rather small energy barrier of $0.19 \mathrm{eV}$. The reaction step is just slightly exothermic by $0.18 \mathrm{eV}$, and the TS is located only slightly above the reference energy level of a separated
$(\mathrm{MgO})_{6}$ cluster and a hydrogen molecule. Note that the situation is similar to ZPE corrected B3LYP $\mathrm{H}_{2}$ dissociation profiles calculated on $\left[(\mathrm{MgO})_{5}\right]^{+}$and $\left[(\mathrm{MgO})_{7}\right]^{+}$clusters, with dissociation energy barriers of 0.31 and $0.19 \mathrm{eV}$, respectively, and slightly exothermic reactions of 0.23 and $0.51 \mathrm{eV}$, respectively. ${ }^{54}$ This means that the dissociation process on $(\mathrm{MgO})_{6}$ cluster is likely to happen even at very low temperatures, given that the energy released during the adsorption process can significantly contribute to overcome the energy barrier for hydrogen dissociation. A completely different situation is found on $\mathrm{MgO}$ surfaces, where the $\mathrm{H}_{2}$ dissociation barrier can be as high as $2.2 \mathrm{eV}$, and, therefore, dissociation can be ruled out at operating temperatures for those cases. ${ }^{55}$ Thus, for the lowcoordinated sites on the $(\mathrm{MgO})_{6}$ cluster, one can envision a steady state situation with an easy dynamic conversion among dissociated and molecular hydrogen, whose population is only governed by the system's thermodynamics.

In the case of $(\mathrm{BeO})_{6}$ the thermodynamics of the reaction changes. Two reaction paths starting from a $\mathrm{X}^{\|}$site are found, yielding $\mathrm{XY}^{\prime}$ and $\mathrm{XY}$ conformations, which are endothermic by 0.28 and $0.34 \mathrm{eV}$, respectively. The reaction step energy barriers for the $\mathrm{H}_{2}$ splitting process are with 0.52 and $0.72 \mathrm{eV}$ both higher than the barriers on $(\mathrm{ZnO})_{6}$ and $(\mathrm{MgO})_{6}$, respectively. Dissociation towards $\mathrm{XY}^{\prime}$ is clearly superior compared to dissociation to a XY site. However, both endothermic processes feature relatively high energy barriers and TS well above the energy reference point, i.e., the dissociation process is likely to be hindered under the above-described conditions. In this particular cluster both thermodynamic and kinetic considerations suggest molecular hydrogen adsorption, making beryllium oxide low-coordinated sites promising active sites for $\mathrm{H}_{2}$ storage.

Finally, the dissociation of $\mathrm{H}_{2}$ adsorbed at a $\mathrm{Y}^{\perp}$ site on $(\mathrm{BaO})_{6}$ towards atomic adsorption in YY geometry has been investigated. For a direct dissociation a second order TS, with a high energy barrier of $2.13 \mathrm{eV}$ is found which, although the process is slightly exothermic by $0.06 \mathrm{eV}$, excludes the possibility of dissociation along this path. An alternative possibility is that the hydrogen molecule initially assumes a XY position, which is accessible via a first order TS lying only $0.30 \mathrm{eV}$ above the $\mathrm{Y}^{\perp}$ energy, followed by a movement of one of the hydrogen atoms from the cation towards a second anion position via a first order TS lying $1.05 \mathrm{eV}$ above the XY level. This complex mechanism has an effective barrier of $1.35 \mathrm{eV}$, which, although quite reduced compared to the direct decomposition, is still rather high compared to the other oxide clusters. In this sense, although thermodynamically both molecular and atomic hydrogen states are similarly stable, the dissociation process is 


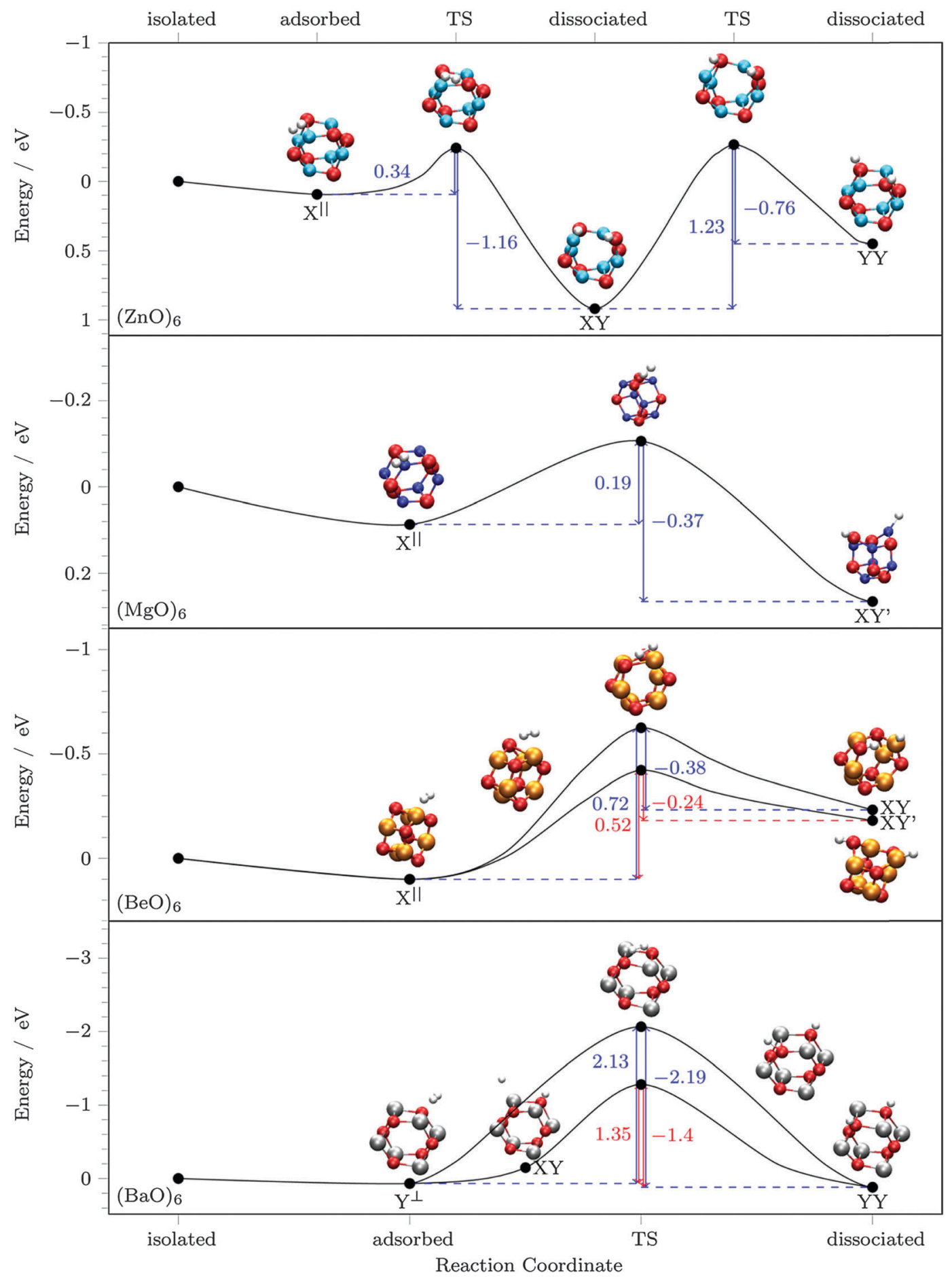

Fig. 5 ZPE corrected energy profiles of $\mathrm{H}_{2}$ adsorption (from the left most point to the $X^{\|}$or $Y^{\perp}$ structure) and dissociation (from $X^{\|}$or $Y^{\perp}$ to the right most point) on the four considered oxide clusters.

kinetically inhibited, and one would envision solely molecular hydrogen under operating conditions.

To further investigate how fast the dissociation kinetics is compared to the adsorption-desorption process-with kinetic constants of the order of $10^{8}-10^{13} \mathrm{~s}^{-1}$-we estimated the rate constants of the reaction steps through transition state theory, using the calculated vibrational frequencies of minima and TS to estimate the entropy contribution to the free energy variation in terms of vibrational partition functions. The rate constant $k-k_{1}$ and $k_{-1}$ for forward and back reactions, respectively-is calculated according to

$$
k=\left(\frac{k_{\mathrm{B}} T}{h}\right)\left(\frac{q^{\#}}{q}\right) \mathrm{e}^{\frac{-E_{\mathrm{barr}}}{k_{\mathrm{B}} T}}
$$


Table 5 Equilibrium and reaction step rate constants for $\mathrm{H}_{2}$ dissociation, hydrogen recombination, and hydrogen diffusion on oxide clusters at fringe operating temperatures of 233 and $333 \mathrm{~K}$

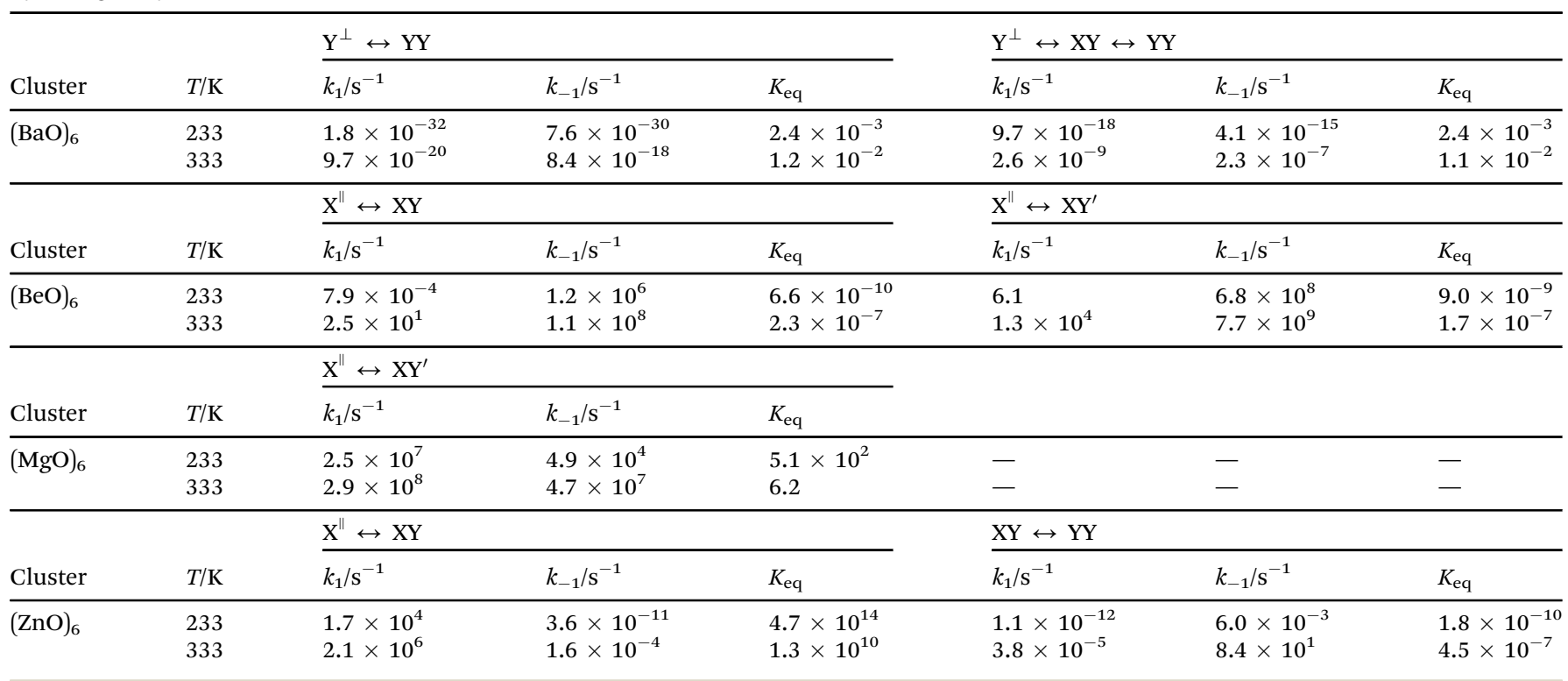

where $k_{\mathrm{B}}$ is the Boltzmann constant, $T$ is the temperature in Kelvin, $q^{\#}$ and $q$ are the vibrational partition functions of the TS and the initial state, respectively, and $E_{\mathrm{barr}}$ is the ZPE corrected energy barrier. The equilibrium constant $K_{\text {eq }}$ for a given reaction step is defined as the ratio $k_{1} / k_{-1}$. Estimates at fringe operating temperatures of 233 and $333 \mathrm{~K}$ are listed in Table 5.

The estimated rate constants are in line with the above predictions. In fact, dissociated $\mathrm{H}_{2}$ seems to be both a thermodynamic and a kinetic sink on the $(\mathrm{ZnO})_{6}$ cluster, since kinetic constants of the reaction step to obtain hydrogen atoms in a XY conformation are relatively high-especially from molecular hydrogen-and the equilibrium constants strongly favor this particular conformation. This prevents the possibility of a fast release of $\mathrm{H}_{2}$ at working conditions.

In the case of $(\mathrm{MgO})_{6}$ both hydrogen dissociation and recombination processes feature high rate constants in the range of $10^{4}-10^{8} \mathrm{~s}^{-1}$, mostly due to the small barrier of $0.19 \mathrm{eV}$ as displayed in Fig. 5. The equilibrium does not lie on one or the other side, and in steady-state situations-when equilibrium between forward and back reactions is achieved-one would expect a significant fraction of molecular hydrogen, although $\mathrm{H}_{2}$ is preferentially found dissociated. Thus, the $\mathrm{H}_{2}$ storage on low-coordinated sites of magnesium oxide is not fully disrupted, since the hydrogen recombination has kinetics close to the desorption process, allowing for a full desorption at reasonable rates.

The $(\mathrm{BeO})_{6}$ cluster exhibits features opposite to the $(\mathrm{ZnO})_{6}$ cluster. Here, the formation of the atomic hydrogen species in a $\mathrm{XY}$ or $\mathrm{XY}^{\prime}$ conformation is impeded mostly due to the relatively high energy barriers. This is in line with dissociation rate constants at operating temperatures of the order of $10^{-4}-10^{1} \mathrm{~s}^{-1}$ and rate constant orders of magnitude higher $-10^{6}-10^{8} \mathrm{~s}^{-1}-$ for the reverse process. In short, despite $\mathrm{H}_{2}$ dissociation is possible, it happens to be both thermodynamically and kinetically hindered, pointing to a molecular hydrogen adsorption, and even a fast recombination of atomic hydrogen traces, if any. In this sense low-coordinated sites as those on the $(\mathrm{BeO})_{6}$ cluster are perfect active sites for $\mathrm{H}_{2}$ storage, with a high adsorption energy of $0.21 \mathrm{eV}$ according to PBE-D3 calculations, rapid desorption kinetics, and thermodynamically and kinetically inhibited $\mathrm{H}_{2}$ dissociation.

Last but not least, the $\mathrm{H}_{2}$ dissociation is essentially prohibited under working conditions for the $(\mathrm{BaO})_{6}$ cluster. The estimated $\mathrm{H}_{2}$ dissociation energy barriers of $1.35 \mathrm{eV}$ and larger are translated into reaction rate kinetic constants of the order of $10^{-9}-10^{-32} \mathrm{~s}^{-1}$ for any of the dissociation paths. This means that despite $\mathrm{H}_{2}$ splitting is almost an isoenergetic process (exothermic by $0.05 \mathrm{eV}$ according to Fig. 5), it is kinetically strongly hindered. Therefore, $\mathrm{H}_{2}$ is likely to be adsorbed in a molecular fashion whenever it is in contact with $(\mathrm{BaO})_{6}$ clusters. Nevertheless, the adsorption energy on the low-coordinated sites of this cluster is at the lowest fringe of the values derived from the analysis of Bhatia and Myers analysis ${ }^{2}$ and, despite the molecular physisorption and the fast desorption kinetics, the $(\mathrm{BaO})_{6}$ cluster suffers from the heavy weight of barium atoms. Indeed, the adsorption of one hydrogen molecule on $(\mathrm{BaO})_{6}$ only represents $0.22 \mathrm{wt} \%$, whereas for lighter metals this percentage is substantially higher, with appealing values of 0.83 and $1.33 \mathrm{wt} \%$ for $(\mathrm{MgO})_{6}$ and $(\mathrm{BeO})_{6}$ clusters, respectively.

\section{Conclusions}

We explored the suitability of different vdW corrections to standard DF calculations for the investigation of $\mathrm{H}_{2}$ physisorption profiles on ionic systems by comparison with $\operatorname{CCSD}(\mathrm{T})$ calculations. To this end we studied a broad set of small magic clusters with common $(\mathrm{XY})_{6}$ formula and drumlike hexagonal shape, 
including oxides $(\mathrm{X}=\mathrm{Mg}, \mathrm{Ba}, \mathrm{Be}, \mathrm{Zn}$ and $\mathrm{Y}=\mathrm{O}$ ), selenides $(\mathrm{X}=\mathrm{Zn}$, Cd and $\mathrm{Y}=\mathrm{Se})$, sulfides $(\mathrm{X}=\mathrm{Zn}$, Cd and $\mathrm{Y}=\mathrm{S})$, halides $(\mathrm{X}=\mathrm{Na}, \mathrm{Li}$ and $\mathrm{Y}=\mathrm{F}, \mathrm{I})$, and the $(\mathrm{BN})_{6}$ nitride. For the most promising composites, the oxide clusters, we compared ionic and atomic parameterizations of the employed vdW corrections.

The vdW correction by Grimme (D3) used in conjunction with the PBE exchange-correlation functional was found to be the best compromise, with adsorption energy profiles similar to those obtained at the $\operatorname{CCSD}(\mathrm{T})$ level. Binding energies of $\mathrm{H}_{2}$ on the low-coordinated sites of the studied oxide clusters were found to be in the range of $0.15-0.21 \mathrm{eV}$, i.e., within the required range for suitable hydrogen storage materials.

$\mathrm{H}_{2}$ dissociation energy profiles reveal that hydrogen is easily dissociated on the low-coordinated sites of $(\mathrm{ZnO})_{6}$, hindering their usage for $\mathrm{H}_{2}$ storage. On $(\mathrm{MgO})_{6}$ hydrogen dissociation is also thermodynamically driven, although by only $0.18 \mathrm{eV}$. The estimated dissociation energy barrier of $0.19 \mathrm{eV}$ allows for a rapid $\mathrm{H}_{2}$ dissociation and recombination, thus leaving the door open for its usage in $\mathrm{H}_{2}$ storage. In the $(\mathrm{BaO})_{6}$ case the $\mathrm{H}_{2}$ dissociation is only marginally endothermic, although the high energy barriers found for the dissociation step strongly suggests the presence of molecular $\mathrm{H}_{2}$ at uptake/release temperatures. On the low-coordinated sites of the $(\mathrm{BeO})_{6}$ cluster, which feature the highest $\mathrm{H}_{2}$ adsorption energy $(0.21 \mathrm{eV})$, a relatively high dissociation energy barrier of $0.52 \mathrm{eV}$ guarantees a rapid $\mathrm{H}_{2}$ uptake/release at moderate pressures with no trace of dissociated hydrogen.

In summary, low-coordinated sites on magnesium, beryllium, and barium oxides reveal very promising properties for hydrogen storage materials. The former two are advantageous in order to accomplish the DOE gravimetric criterion for hydrogen storage due to the small mass of magnesium and beryllium atoms, although utilization of beryllium oxide must be handled with care due to its known toxicity. ${ }^{58}$

Finally, the computationally affordable PBE-D3 method seems to be suitable for future $\mathrm{H}_{2}$ adsorption studies on $\mathrm{BeO}$, $\mathrm{BaO}, \mathrm{MgO}$, and $\mathrm{ZnO}$ systems in particular, and other metal oxides in general. Furthermore, low-coordinated sites of such oxides and other light alkali and earth alkali oxides are introduced as promising active centers for $\mathrm{H}_{2}$ storage materials, especially when meeting the gravimetric criterion. Further work can be envisioned considering similar clusters to the ones studied here, since those can already be found as nodes in MOFs, ${ }^{51,52}$ but, in light of the present results, it also seems desirable to study other isolated (one-dimensional) materials, such as other magic clusters. ${ }^{15,59,60}$ Moreover, two-dimensional materials like beaded nanoclusters or nanowires are also promising materials containing a high-density of low-coordinated sites. ${ }^{61,62}$ Last but not least, recent theoretical studies have presented many three-dimensional low-density polymorphs of $\mathrm{ZnO}, \mathrm{BeO}, \mathrm{MgO}$, and $\mathrm{BaO}$, with zeolite-like structures close in energy to the most stable polymorphs, ${ }^{59,63-65}$ which add to the excitement of finding an economic metal oxide composite with a high density of low-coordinated metal sites as the holy grail for $\mathrm{H}_{2}$ storage.

\section{Acknowledgements}

We thank the German Research Council (DFG) which supports, within the framework of its Excellence Initiative, the Cluster of Excellence "Engineering of Advanced Materials" (www.eam. uni-erlangen.de) and the Research Unit 1878 "funCOS Functional Molecular Structures on Complex Oxide Surfaces". F.V. thanks the MINECO for a postdoctoral Juan de la Cierva grant (JCI-2010-06372), and the Alexander von Humboldt Foundation for financing his postdoctoral grant.

\section{References}

1 http://www1.eere.energy.gov/hydrogenandfuelcells/storage/ current_technology.html.

2 S. K. Bhatia and A. L. Myers, Langmuir, 2006, 22, 1688-1700. 3 M. P. Suh, H. J. Park, T. K. Prasad and D.-W. Lim, Chem. Rev., 2012, 112, 782-835.

4 Y. H. Hu, N. Y. Yu and E. Ruckenstein, Ind. Eng. Chem. Res., 2004, 43, 4174-4177.

5 C. H. Christensen, R. Z. Sørensen, T. Johannessen, U. J. Quaade, K. Honkala, T. D. Elmøe, R. Køhler and J. K. Nørskov, J. Mater. Chem., 2005, 15, 4106-4108.

6 H. Lee, J.-W. Lee, D. Y. Kim, J. Park, Y.-T. Seo, H. Zeng, I. L. Moudrakovski, C. I. Ratcliffe and J. A. Ripmeester, Nature, 2005, 434, 743-746.

7 Y.-H. P. Zhang, Int. J. Hydrogen Energy, 2010, 35, 10334-10342.

8 L. Schlapbach and A. Züttel, Nature, 2001, 414, 353-358.

9 H. Takagi, H. Hatori, Y. Snoeda, N. Yoshizawa and Y. Yamada, Mater. Sci. Eng., 2004, 108, 143-147.

10 W. H. Shin, S. H. Yang, W. A. Goddard III and J. K. Kang, Appl. Phys. Lett., 2006, 88, 053111.

11 T. Yildirim, J. Íñiguez and S. Ciraci, Phys. Rev. B: Condens. Matter Mater. Phys., 2005, 72, 153403.

12 P. Bernard, R. Chahine, P. A. Chandonia, D. Cossement, G. Dorval-Douville, L. Laft, P. Lachance, R. Paggiaro and E. Poirier, J. Alloys Compd., 2007, 446, 380-384.

13 O. K. Farha, A. O. Yazaydin, I. Eryazici, C. D. Malliakas, B. G. Hauser, M. G. Kanatzidis, S. T. Nguyen, R. Q. Snurr and J. T. Hupp, Nat. Chem., 2010, 2, 944-948.

14 R. E. Morris and P. S. Wheatley, Angew. Chem., Int. Ed., 2008, 47, 4966-4981.

15 C. R. A. Catlow, S. T. Bromley, S. Hamad, M. Mora-Fonz, A. A. Sokol and S. M. Woodley, Phys. Chem. Chem. Phys., 2010, 12, 786-811.

16 W. A. Saunders, Phys. Rev. B: Condens. Matter Mater. Phys., 1988, 37, 6583-6586.

17 P. J. Ziemann and A. W. Castleman Jr., J. Chem. Phys., 1991, 94, 718-727.

18 S. Kristyán and P. Pulay, Chem. Phys. Lett., 1994, 229, 175-180.

19 F. Ortmann, F. Bechstedt and W. G. Schmidt, Phys. Rev. B: Condens. Matter Mater. Phys., 2006, 73, 205101.

20 S. Grimme, J. Antony, S. Ehrlich and H. Krieg, J. Chem. Phys., 2010, 132, 154104. 
21 T. van Mourik and R. J. Gdanitz, J. Chem. Phys., 2002, 116, 9620-9623.

22 J. Toda, M. Fischer, M. Jorge and J. R. B. Gomes, Chem. Phys. Lett., 2013, 587, 7-13.

23 G. Kresse and J. Furthmüller, Phys. Rev. B: Condens. Matter Mater. Phys., 1996, 54, 11169-11186.

24 P. E. Blöchl, Phys. Rev. B: Condens. Matter Mater. Phys., 1994, 50, 17953-17979.

25 S. H. Vosko, L. Wilk and M. Nusair, Can. J. Phys., 1980, 58, 1200-1211.

26 L. Goerigk, H. Kruse and S. Grimme, ChemPhysChem, 2011, 12, 3421-3433.

27 J. Gebhardt, F. Viñes and A. Görling, Phys. Rev. B: Condens. Matter Mater. Phys., 2012, 86, 195431.

28 S. M. Kozlov, F. Viñes and A. Görling, J. Phys. Chem. C, 2012, 116, 7360-7366.

29 J. Gebhardt, R. J. Koch, W. Zhao, O. Höfert, K. Gotterbarm, S. Mammadov, C. Papp, A. Görling, H.-P. Steinrück and Th. Seyller, Phys. Rev. B: Condens. Matter Mater. Phys., 2013, 87, 155437.

30 J. E. Huheey, E. A. Keiter and R. L. Keiter, Inorganic Chemistry: Principles of Structure and Reactivity, Harper Collins, New York, USA, 4th edn, 1993.

31 A. D. Becke, J. Chem. Phys., 1993, 98, 5648-5652.

32 TURBOMOLE, TURBOMOLE GmbH, Karlsruhe, 2012, at http://www.turbomole.com.

33 S. Ehrlich, J. Moellmann, W. Reckien, T. Bredow and S. Grimme, ChemPhysChem, 2011, 12, 3414-3420.

34 T. H. Dunning Jr., J. Chem. Phys., 1989, 90, 1007-1023.

35 F. Weigend, A. Köhn and C. Hättig, J. Chem. Phys., 2002, 116, 3175-3183.

36 F. Weigend and R. Ahlrichs, Phys. Chem. Chem. Phys., 2005, 7, 3297-3305.

37 M. Kaupp, P. v. R. Schleyer, H. Stoll and H. Preuss, J. Chem. Phys., 1991, 94, 1360-1366.

38 A. Hellweg, C. Hättig, S. Höfener and W. Klopper, Theor. Chem. Acc., 2007, 117, 587-597.

39 G. Henkelman, B. P. Uberuaga and H. Jónsson, J. Chem. Phys., 2000, 113, 9901-9904.

40 G. Henkelmann and H. Jónsson, J. Chem. Phys., 1999, 111, 7010-7022.

41 L. Adamska, Y. Lin, A. J. Ross, M. Batzill and I. I. Oleynik, Phys. Rev. B: Condens. Matter Mater. Phys., 2012, 85, 195443.

42 F. Viñes, J. Carrasco and S. T. Bromley, Phys. Rev. B: Condens. Matter Mater. Phys., 2012, 85, 195425.
43 B. Wang, S. Nagase, J. Zhao and G. Wang, J. Phys. Chem. C, 2007, 111, 4956-4963.

44 L. Ren, L. Cheng, Y. Feng and X. Wang, J. Chem. Phys., 2012, 137, 014309.

45 F. Bawa and I. Panas, Phys. Chem. Chem. Phys., 2002, 4, 103-108.

46 E. Sanville, A. Burnin and J. J. BelBruno, J. Phys. Chem. A, 2006, 110, 2378-2386.

47 S. Hamad, C. R. A. Catlow, E. Spanó, J. M. Matxain and J. M. Ugalde, J. Phys. Chem. B, 2005, 109, 2703-2709.

48 A. Aguado, A. Ayuela, J. M. López and J. A. Alonso, Phys. Rev. B: Condens. Matter Mater. Phys., 1997, 56, 15353-15360.

49 A. Aguado, A. Ayuela, J. M. López and J. A. Alonso, J. Phys. Chem. B, 1997, 101, 5944-5950.

50 M. G. Giuffreda, M. S. Deleuze and J.-P. François, J. Phys. Chem. A, 2000, 104, 5855-5860.

51 S. S. Han, W.-Q. Deng and W. A. Goddard III, Angew. Chem., Int. Ed., 2007, 46, 6289-6292.

52 F. M. Mulder, T. J. Dingemans, M. Wagemaker and G. J. Kearley, Chem. Phys., 2005, 317, 113-118.

53 H.-S. Chen and H.-J. Chen, Acta Phys. Sin., 2011, 60, 073601. 54 K. Kwapien, M. Sierka, J. Döbler and J. Sauer, ChemCatChem, 2010, 2, 819-826.

55 G. Wu, J. Zhang, Y. Wu, Q. Li, K. Chou and X. Bao, J. Alloys Compd., 2009, 480, 788-793.

56 G. Henkelman, A. Arnaldsson and H. Jonsson, Comput. Mater. Sci., 2006, 36, 354-360.

57 Y. Wang, B. Meyer, X. Yin, M. Kunat, D. Langenberg, F. Traeger, A. Birkner and C. Wöll, Phys. Rev. Lett., 2005, 95, 266104.

58 R. Puchta, Nat. Chem., 2011, 3, 416.

59 J. Carrasco, F. Illas and S. T. Bromley, Phys. Rev. Lett., 2007, 99, 235502.

60 K. Kwapien, M. Sierka, J. Döbler, J. Sauer, M. Haertelt, A. Fielicke and G. Meijer, Angew. Chem., Int. Ed., 2011, 50, 1716-1719.

61 S. Zhang, Y. Zhang, S. Huang, H. Liu, P. Wang and H. Tian, J. Mater. Chem., 2011, 21, 16905-16910.

62 L.-B. Shi, M.-B. Li and Y. Fei, Solid State Sci., 2013, 16, 21-28.

63 J. C. Schön, Z. Anorg. Allg. Chem., 2004, 630, 2354-2366.

64 M. A. Zwijnenburg, F. Illas and S. T. Bromley, Phys. Rev. Lett., 2010, 104, 175503.

65 I. Demiroglu, S. Tosoni, F. Illas and S. T. Bromley, Nanoscale, 2014, 6, 1181-1187. 